\title{
ORAL MIFEPRISTONE AS A LABOUR INDUCING CERVICAL PRIMING AGENT
}

\section{Dr. M. Mareeswari}

\section{Dr. Damayanthi*}

Assistant Professor, Department Of Obstetrics And Gynaecology Tirunelveli Govt Medical College Hospital

Assistant Professor, Department Of Obstetrics And Gynaecology Tirunelveli Govt Medical College Hospital. ${ }^{\star}$ Corresponding Author

\section{ABSTRACT INTRODUCTION: Mifepristone is a 19 nor-Steroid, progestational and glucocorticoid hormone} antagonist. During onset of spontaneous labour, there will be fall in the progesterone level, which is one of the most important event. Oral mifepristone progestational antagonist may be useful in induction of labour.

AIM: To study the effectiveness and safety of Mifepristone as a cervical priming agent for induction of labour by comparing the effect of mifepristone in study group with a control group of same size and to determine the Maternal and fetal outcome.

METHODOLOGY: This prospective clinical trial was carried out in the Department of Obstetrics and Gynecology, K.A.P.V Medical college \& Mahatma Gandhi Memorial Hospital, Trichy during the period of June 2015 to November 2016 in 100 patients divided into study and control group equally.

RESULTS: In this study, study population comprised of 100 patients with equal number of patients in the study and control group. There were no significant statistical differences between the treatment groups in demographics or medical or obstetrics history. Age distribution is also not statistically significant $(p>0.05)$ Hence both the groups are comparable. The difference in distribution of the study population according to parity was not statistically significant $(p>0.05)$ between the groups. Subjects in the Mifepristone group were not so different from subjects in placebo group with the respect to Bishop score at baseline as the mean difference is not statistically significant $(\mathrm{p}>0.05)$. However, Subjects in the Mifepristone group had a higher Bishop score after 24 hours than subjects in placebo group and this mean difference is statistically significant. Subjects in the Mifepristone group progressed about 6 hours (mean difference) earlier than subjects in placebo group to active stage of labor and this difference is statistically significant. Also the use of oral mifepristone shortened the duration from induction to active stage ranging from 5 hours to 7 hours based on the $95 \%$ confidence interval. Subjects in the Mifepristone group progressed to delivery in about 7 hours (mean difference) earlier than subjects in placebo group and this difference is statistically significant.

CONCLUSION: From the study we conclude that mifepristone as a labour inducing cervical ripening agent had a better proven efficacy especially in primigravida women as similarly proved by various other earlier standard trials. The results from the studies are encouraging with no significant adverse effects on mother and fetus.

\section{KEYWORDS : Mifepristone, Bishop Score, Induction.}

\section{INTRODUCTION:}

Induction of labour has two important components, cervical ripening and stimulation of uterine contractions to achieve dilatation of cervix and delivery of the fetus. Agents used for cervical ripening may lead to the establishment of contractions in women with unfavorable cervix. Mifepristone is a 19 nor-Steroid, progestational and glucocorticoid hormone antagonist. It has great affinity for the progesterone receptor and it blocks the action of progesterone at a cellular level. During onset of spontaneous labour, there will be fall in the progesterone level, which is one of the most important event. Oral mifepristone progestational antagonist may be useful in induction of labour

\section{AIM OF STUDY:}

To study the effectiveness and safety of Mifepristone as a cervical priming agent for induction of labour by comparing the effect of mifepristone in study group with a control group of same size and to determine the Maternal and fetal outcome.

\section{INCLUSION CRITERIA:}

Singleton pregnancy in cephalic presentation, Term uncomplicated pregnancies with unfavourable cervix (Bishop score <4), Intra uterine fetal death, Gestational hypertension, Intact membranes during the time of induction.

\section{EXCLUSION CRITERIA:}

Premature rupture of membranes, Contraindications for prostaglandins or mifepristone, Malpresentations, Elderly primi gravida (age $>35$ years), Cephalopelvic disproportion, Multiple pregnancy, Bad obstetric history or history of previous abortions, Oligohydramnios, Previous history of caesarean section or any uterine surgery, Patients who underwent caesarean section after induction.

\section{METHOD OF STUDY}

This prospective clinical trial was carried out in the Department of Obstetrics and Gynaecology, K A P V Govt Medical college and Mahatma Gandhi memorial hospital, Trichy during the period of June 2015 to November 2016. Hundred pregnant women divided into two groups (Group M \& Group P) with 50 pregnant women on each group.

Group M: Administered Tab.Mifepristone 200mg orally on dayl. The following parameters were observed. Maternal vitals, Uterine activity, Bleeding or Draining per vaginum and Fetal heart rate. They were observed for the period of 24 hours or when the Bishop score is $\geq 6$ with cervical dilatation $>2 \mathrm{~cm}$, or when the membranes ruptured or when the patient is well in labour whichever is earlier. Pregnant women in early labour is accelerated with oxytocin drip.

Group II: Administered placebo on day 1. The following parameters were observed. Maternal vitals, Uterine activity, Bleeding or draining per vaginum and Fetal heart rate. They were observed for the period of 24 hours, depending on the Bishop score they were either induced with cerviprime gel or augmented with oxytocin drip.

\section{RANDOMIZATION: CLOSED ENVELOPE TECHNIQUE}

100 plain covers each with a single sheet written $M$ for oral mifepristone in 50 sheets, written $\mathrm{P}$ for placebo in 50 sheets were prepared. The covers were mixed thoroughly. Before start of the induction the patient picked up a cover of their choice and were randomized accordingly.

\section{MONITORING OF THE PATIENTS:}

Maternal vitals- Blood pressure , pulse rate, temperature were monitored with the help of philps sursign multiparamonitor. 
Uterine activity, Bleeding or Draining per vaginum and Fetal heart rate were monitored clinically. Clinical events and progression of labour is monitored with partogram for all patients. Watch for the rupture of membranes. ARM done after $4 \mathrm{~cm}$ of cervical dilatation if membrane not ruptured spontaneously. Duration of each stage of labour, blood loss at third stage of labour and APGAR score of the baby were recorded. Mother and baby were observed for postnatal complications if any and were resuscitated appropriately.

BLINDING : Double blinded- Both the patient and observer were blinded

\section{DATA ANALYSIS:}

Data were analysed and Statistical comparison were performed by using students paired and unpaired t-test and chi-square test. Statistically significant difference $(P<0.05)$ were noted.

The efficacy is assessed by the following criteria:

1. Favourability of Bishop score at $24 \mathrm{hrs}$.

2. Need for induction with cerviprime gel.

3. The need of oxytocin for augmentation.

4. Duration of labour.

5. Drug administration to delivery interval.

6. The mode of delivery.

\section{The Safetiness is assessed by following criteria}

1. Apgar score

2. Neonatal complications if any

3. maternal complications.

Success of induction is defined by:

Patients who delivered vaginally within 48 hours at the start of induction or Bishop score of $\geq 6$ at the end of 24 hours

Failure of induction is defined by:

Patients who delivered vaginally after 48 hours at the start of induction. Patients who underwent caesarean section.

\section{RESULTS:}

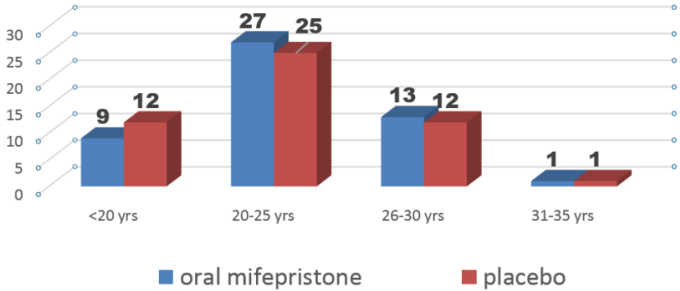

Mean age: 23.48 years, Standard deviation: 3.514 years

Fig 1: Bar chart showing age distribution of the study population $(n=100)$

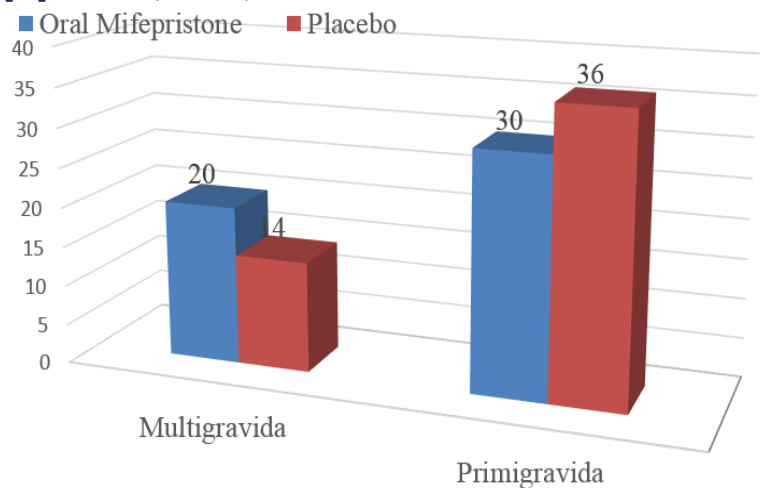

Fig 2: Bar chart showing distribution of the study population according to parity $(n=100)$

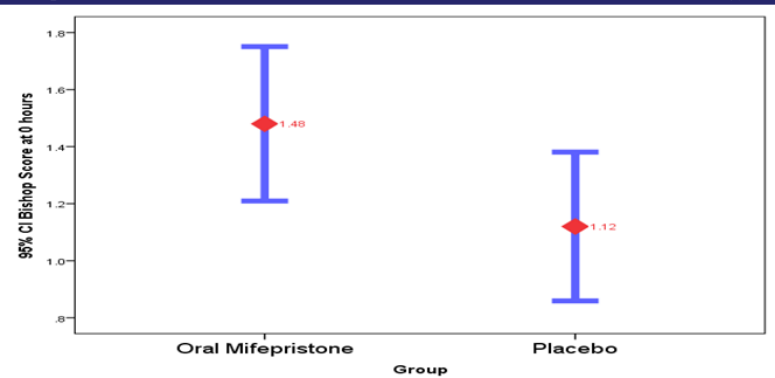

Fig 3: Box plot showing distribution of the study population according to bishop score at 0 hours among the two groups $(n=100)$

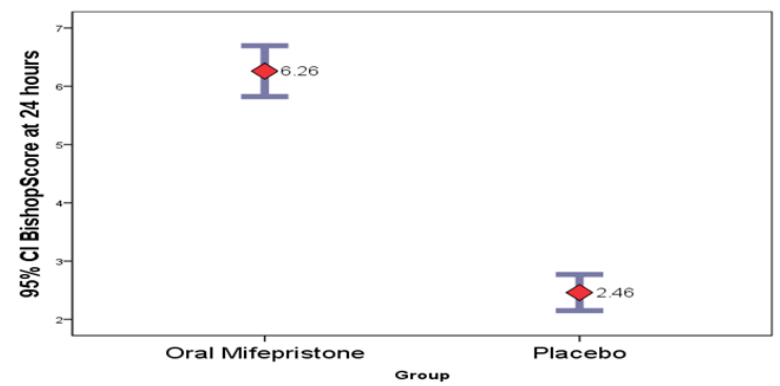

Fig 4: Box plot showing distribution of the study population according to bishop score at 24 hours among the two groups $(\mathrm{n}=100)$

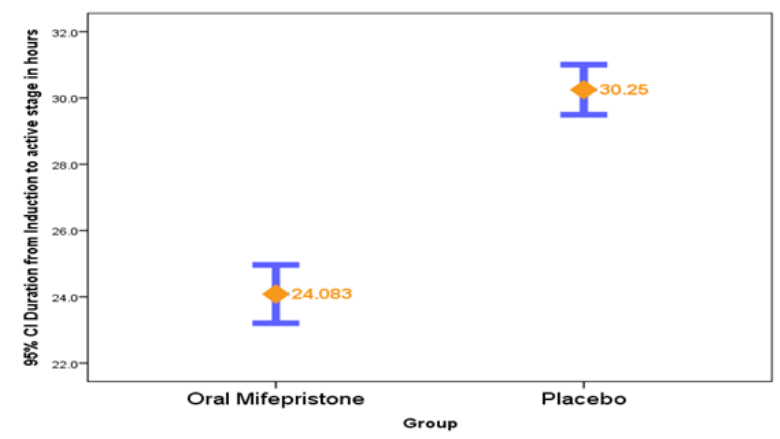

Fig 5: Box plot of time duration from induction to active stage of labor among the two groups $(n=84)$

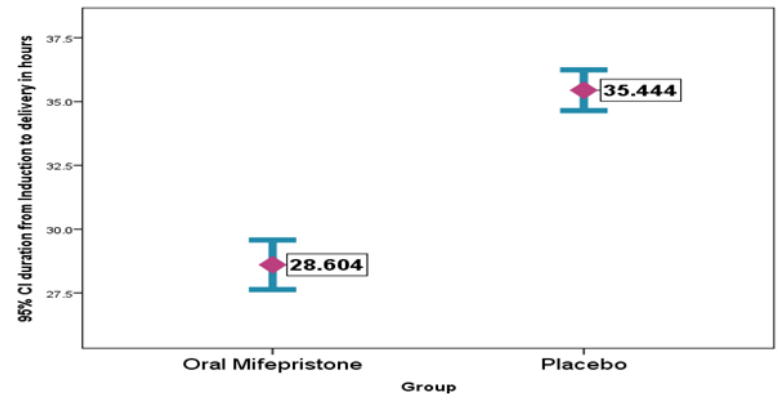

Fig 6: Box plot of time duration from induction to delivery of labor among the two groups $(n=84)$

\section{DISCUSSION:}

Our study population comprised of 100 patients with equal number of patients (50 each) in the study and control group. There were no significant statistical differences between the treatment groups in demographics or medical or obstetrics history.

Age distribution of the 2 groups were similar (Chi-square value: $0.502, p$ value: 0.918 ) and the minor difference observed was not statistically significant ( $p>0.05)$ (Fig 1). Hence both the groups are comparable. The difference in distribution of the study population according to parity (Chi- 
square value: $1.604, p$ value: 0.205 ) is not statistically significant $(p>0.05)$ between the groups. Hence both the groups are comparable (Fig 2).

The difference in indications for induction of labor (Chisquare value: $0.377, \mathrm{p}$ value: 0.828 ) is not statistically significant $(p>0.05)$ between the groups. Subjects in the Mifepristone group were not so different from subjects in placebo group with the respect to Bishop score at baseline as the mean difference $(0.360)$ ( $p$ value- 0.057 ) is not statistically significant $(p>0.05)$ (Fig 3 ).

However, Subjects in the Mifepristone group had a higher Bishop score after 24 hours than subjects in placebo group and this mean difference $(3.80)$ ( $p$ value- $<0.001$ ) is statistically significant (Fig 4). Very few Subjects in the Mifepristone needed cervical priming with Dinoprostone gel than subjects in placebo group and this difference is statistically significant (Chi-square value: $58.604, \mathrm{p}$ value: $<0.001)$.

Hence the use of oral Mifepristone greatly reduces the need for cervical priming with Dinoprostone gel. The difference in mode of delivery is statistically significant $(p>0.05)$ (Chisquare value: 12.179 , $p$ value: 0.002 ) between the 2 groups with fewer subjects in the mifepristone group needing LSCS. Subjects in the Mifepristone group progressed about 6 hours (mean difference) earlier than subjects in placebo group to active stage of labor and this difference was statistically significant ( $\mathrm{p}$ value $<0.001$ ). Also the use of oral mifepristone shortened the duration from induction to active stage ranging from 5 hours to 7 hours based on the $95 \%$ confidence interval (Fig 5).

Subjects in the Mifepristone group progressed to delivery in about 7 hours (mean difference) earlier than subjects in placebo group and this difference is statistically significant(p value $<0.001$ ) Also the use of oral mifepristone shortened the duration from induction to delivery in the range of 5 hours 30 minutes to 8 hours based on the $95 \%$ confidence interval. About $23 \%$ of patients who were given oral mifepristone delivered within 24 hours while all the patients in the placebo group delivered between 25 to 48 hours duration from induction and this difference is statistically significant (Chisquare value: 9.493 , p value: 0.002 ).

There is a statistically significant difference in the mean apgar score between the 2 groups both at 0 minutes and 5 minutes with babies born to the subjects in the Mifepristone group having a better apgar score than those born to the subjects in placebo group mean difference $(0.460)$ and $p$ value 0.003. The difference in occurrence of fetal complications is not statistically significant $(p>0.05)$ between the 2 groups (Chi-square value: 2.589 , p value: 0.459 )

\section{CONCLUSION:}

From the study we conclude that mifepristone as a labour inducing cervical ripening agent had a better proven efficacy especially in primigravida women as similarly proved by various other earlier standard trials. Need for a Reinduction/augmentation with other cerviprime agents/oxytocics is reduced in the mifepristone treated groups. The results from the studies are encouraging with no significant adverse effects on mother and fetus. Need for further studies to compare the efficacy of $200 \mathrm{mg}$ of mifepristone with $400 \mathrm{mg}$ or even higher doses if found favourable.

\section{REFERENCES:}

1. Williams obstetrics 24rth Edition, F Gary Cunnigham, Kenneth J. Leveno, Steven L. Bloom, Spong,Dashe,Hoffman,Casey,Sheffield, Section VII Chapter 26 Induction and augmentation Of labour-Pg 525

2. D.K. James, P.J. Steer, C.P.Weiner, B. Gonik, High risk pregnancy management options, Third edition Elsevier Section Six, chapter 68, Induction of labour and pregnancy Termination for fetal abnormality

3. Arulkumaran, Leonie K. Penna K. Bhasker Rao, The management of Labour Second edition, Chapter 1, Physiopharmacology of labour Pg. 11, 12, 14 chapter 18 Induction of labour 281, 292-296, 2007

4. Leon speroff and marc A. Fritz clinical gynecologic endocrinology and infertility VII edn.

5. Haney. Ingrid Nygaard wolter kluwer/ ch.11 Preterm labour and post term deliveries - Pg 167.

6. Danforth's obs and Gyn 10th edn Ronald S. Gibhs Beth Y. Karlan, Arthur

7. R.S. Satoskar, S.D Bhandarkar, Nirmala N. Rege Pharmacology Pharmacotherapeutics, Popular Prakashan 25th edition Antifertility agents and Ovulation inducing drugs $\mathrm{Ch}-66$ - Pg 956.

8. Cabrol, D., Dubois, C., Cranje, H., et al. Induction of labor with mifepristone (RU-486) in intrauterine fetal death. American Journal of Obstertrics and Gynecology 162:540-542

9. Clinical Obstetrics and Gynecology, cervical ripening and labour induction September 2006 Deborah Lippincott williancs and wilkins, New application of mifepristone Stevehondon June 06 Volm 39 No.2

10. Berkane N, Verstraete L, Uzan S, et al. Use of mifepristone to ripen the cervix and induce labor in term pregnancies. Am J Obstet Gynecol. 2005; 192(1):114 120.

11. Frydman, R.C., Lelaidier, C., Baton-Saint-Mleux, C., et al. Labor induction in women at term with mifepristone (RU-486): A double-blind, randomized, placebo-controlled study. Obstertrics and Gynecology 80:972-975, 1992. 